\title{
Extracorporeal blood purification for sepsis
}

\author{
HP Shum *, WW Yan, TM Chan
}

This article was published on 19 Aug 2016 at www.hkmj.org.

\section{A B S T R A C T}

It has been speculated that extracorporeal blood purification therapies might improve the clinical outcome for patients with severe sepsis, with or without acute kidney injury, since the removal of inflammatory mediators and/or bacterial toxins from circulation could modulate the inflammatory responses that result in organ damage. Despite initial enthusiasm based on promising preliminary results, subsequent investigations did not show sustainable survival benefit. We review the principles and development of blood purification techniques for sepsis and septic acute kidney injury.

\section{Hong Kong Med J 2016;22:478-85}

DOI: 10.12809/hkmj164876

${ }^{1}$ HP Shum *, FRCP, FHKAM (Medicine)

${ }^{1}$ WW Yan, FRCP, FHKAM (Medicine)

${ }^{2}$ TM Chan, MD, FHKAM (Medicine)

${ }^{1}$ Department of Intensive Care, Pamela Youde Nethersole Eastern Hospital, Chai Wan, Hong Kong

2 Department of Medicine, The University of Hong Kong, Queen Mary

Hospital, Pokfulam, Hong Kong

* Corresponding author: shumhp@ha.org.hk

\section{Introduction}

The concepts underlying the pathogenesis of septic acute kidney injury (AKI) are complex. It is characterised by renal macro- and microcirculatory disturbance, surge of inflammatory markers, and de-regulation of oxidative stress, followed by a bioenergetic adaptive response and controlled cell cycle arrest aimed at preventing cell death. ${ }^{1}$ Continuous renal replacement therapy is commonly performed in the critical care setting for patients with septic AKI. The use of low- or normalvolume continuous venovenous haemodialysis or haemofiltration, however, has failed to demonstrate any improvement of patient outcome in severe sepsis. ${ }^{2,3}$ Extracorporeal blood purification therapies have been proposed to improve the outcome for patients with severe sepsis with and without AKI. The underlying principle is the removal of excessive inflammatory mediators and/or bacterial toxins from the blood compartment in order to modulate the inflammatory response. This involves various techniques including haemoperfusion/ haemoadsorption, high-adsorption haemofiltration, high-volume haemofiltration (HVHF), high cut-off (HCO) membrane haemofiltration/haemodialysis, plasma exchange, and coupled plasma filtration adsorption (CPFA) [Table 1]. These techniques are gaining popularity in Europe and Japan. This overview discusses the concept and latest advances in blood purification for sepsis and septic AKI.

\section{Therapeutic concept of extracorporeal blood purification}

During sepsis, triacylated peptides, diacylated peptides, or lipopolysaccharides (LPS) are released by pathogens, and are recognised by the Tolllike receptors located on the surface of antigenpresenting cells. ${ }^{4,5}$ Toll-like receptors also recognise locally produced damage-associated molecular patterns (DAMPs) from ischaemic renal tissue and circulating DAMPs released from extensive extrarenal tissue damage in sepsis. ${ }^{6}$ This triggers the activation of leukocytes, endothelial cells, and epithelial cells that release more inflammatory mediators such as tumour necrosis factor-alpha (TNF- $\alpha$ ), interleukin-1 (IL-1), IL-6, IL-8 and IL-10, causing cellular and tissue damage. ${ }^{7,8}$ This is called a 'cytokine storm', and can also occur in non-infectious conditions such as severe trauma, extensive burns, acute necrotising pancreatitis, and post-cardiac arrest. A cytokine storm per se, in the absence of life-threatening triggering factors, can induce haemodynamic instability and multi-organ failure as illustrated by Suntharalingam et al. ${ }^{9}$ Moreover, immunoparalysis might occur after a cytokine storm and contribute to severe secondary nosocomial infections. ${ }^{10}$ As demonstrated in a postmortem by Boomer et al, ${ }^{11}$ patients who die of severe sepsis have biochemical and immunohistochemical findings consistent with immunosuppression. This gives rise to the concept of immunomodulation in sepsis. Low-dose steroid administration has been shown to improve septic shock reversal but is not associated with any survival benefits and is currently out of favour. ${ }^{12,13}$ The clinical benefit of intravenous immunoglobulins and anti-TNF- $\alpha$ in the treatment of severe sepsis is controversial and inconclusive. ${ }^{14,15}$ Blood purification may offer non-specific clearance of inflammatory mediators and/or microbial toxins and thus help to restore immune homeostasis. Five theories have been proposed to explain the potential 
benefit of blood purification in sepsis. First, Ronco et $\mathrm{al}^{16}$ proposed the "cytokine peak concentration hypothesis" and suggested that eliminating the peaks in cytokine blood concentration during the early phase of sepsis could stop the inflammatory cascade, limit organ damage, and consequently decrease the incidence of multi-organ failure syndrome. Second, Honoré and Matson ${ }^{17}$ proposed the "threshold immunomodulation hypothesis" that indicated cytokines will equilibrate between the blood and tissue compartments. This provided an explanation for the clinical benefit of blood purification techniques even without any significant changes in cytokine level within the blood compartment. Third, Di Carlo and Alexander ${ }^{18}$ proposed the "mediator delivery hypothesis" and suggested that high-volume fluid replacement during haemofiltration might promote lymphatic flow and displace inflammatory mediators to the blood compartment, making them available for removal. Fourth, Peng et $\mathrm{al}^{19}$ suggested that blood purification therapies could act directly at the cellular level to restore immune function. Finally, Rimmelé and Kellum ${ }^{20}$ proposed the "cytokinetic model" which indicated that blood purification techniques remove cytokines from the blood compartment and widen the cytokine/chemokine concentration gradient between blood and infected tissue. This improves leukocyte trafficking towards

\section{體外血液淨化療法治療膿毒症} 沈海平、殷榮華、陳德茂

體外血液淨化療法能去除血液中過多炎症介質和/或細菌毒素以達至調 節炎症反應效果, 因此被推測在有或沒有急性腎損傷情況下能改善嚴 重膿毒症的治療效果。初期研究的結果令人鼓舞, 可惜及後的研究未 能證實可延長病人的存活。本文回顧體外血液淨化療法對於膿毒症及 膿毒性急性腎損傷的原理和發展。

the infective foci, and thus promotes bacterial killing.

\section{Haemoperfusion/haemoadsorption}

This technique binds toxins and other mediators in the extracorporeal circuit and removes them from the blood compartment. ${ }^{20}$ The sorbents, which consist of microfibres or resin-covered beads, are normally contained in cartridges that are placed in series within the extracorporeal circuit. They have a selective or non-selective binding capacity for cytokines, chemokines, super-antigens, or endotoxins by means of hydrophobic interaction, van der Waals forces, or ionic interactions. ${ }^{20}$ Initial clinical applications were complicated by severe thrombocytopenia and leukopenia but these were

TABLE I. Comparison between major blood purification techniques

\begin{tabular}{|c|c|c|}
\hline Therapy & Mode of action & Comments \\
\hline $\begin{array}{l}\text { Polymyxin B-immobilised fibre column } \\
\text { (Toraymyxin; Toray Industries, Tokyo, Japan) }\end{array}$ & Endotoxin haemoadsorption & $\begin{array}{l}\text { - Potential mortality benefit based on RCTs } \\
\text { - Well-studied treatment modality } \\
\text { - Not available locally }\end{array}$ \\
\hline $\begin{array}{l}\text { MATISSE-Fresenius system (Fresenius SE, } \\
\text { Bad Homburg, Germany) }\end{array}$ & Endotoxin haemoadsorption & $\begin{array}{l}\text { - Multicentre RCT showed no significant clinical } \\
\text { benefit }\end{array}$ \\
\hline $\begin{array}{l}\text { Alteco LPS Adsorber (Alteco Medical AB, } \\
\text { Lund, Sweden) }\end{array}$ & Endotoxin haemoadsorption & $\begin{array}{l}\text { - Limited clinical experience } \\
\text { - Ex-vivo study showed unacceptable LPS clearance }\end{array}$ \\
\hline Cytokines haemoadsorptive device & Cytokine haemoadsorption & $\begin{array}{l}\text { - Good cytokine clearance } \\
\text { - Limited clinical experience }\end{array}$ \\
\hline $\begin{array}{l}\text { oXiris haemofilter (Gambro Hospal, Stockholm, } \\
\text { Sweden) }\end{array}$ & $\begin{array}{l}\text { Endotoxin and cytokine haemoadsorption } \\
\text { plus renal support }\end{array}$ & $\begin{array}{l}\text { - Simple and familiar technique } \\
\text { - Limited clinical experience }\end{array}$ \\
\hline PMMA haemofilter & $\begin{array}{l}\text { Cytokine haemoadsorption plus renal } \\
\text { support }\end{array}$ & $\begin{array}{l}\text { - Simple and familiar technique } \\
\text { - No RCT available } \\
\text { - Low cost }\end{array}$ \\
\hline HVHF & Haemofiltration & $\begin{array}{l}\text { - Well-studied treatment modality } \\
\text { - No survival or haemodynamic benefit }\end{array}$ \\
\hline High cut-off haemofiltration/haemodialysis & $\begin{array}{l}\text { Cytokine removal by haemofiltration/ } \\
\text { haemodialysis }\end{array}$ & $\begin{array}{l}\text { - Simple and familiar technique } \\
\text { - One unpublished RCT showed no mortality or other } \\
\text { clinical benefit }\end{array}$ \\
\hline Plasmapheresis & Cytokine removal by haemofiltration & $\begin{array}{l}\text { - Conflicting results from RCTs } \\
\text { - Loss of vital component during prolonged treatment }\end{array}$ \\
\hline CPFA & $\begin{array}{l}\text { Cytokine removal by haemofiltration and } \\
\text { haemoadsorption }\end{array}$ & $\begin{array}{l}\text { - One RCT showed no mortality benefit } \\
\text { - More complicated setup when compared with other } \\
\text { blood purification techniques }\end{array}$ \\
\hline
\end{tabular}

Abbreviations: CPFA = coupled plasma filtration adsorption; HVHF = high-volume haemofiltration; LPS = lipopolysaccharides; PMMA = polymethylmethacrylate; $\mathrm{RCT}=$ randomised controlled trial 
subsequently managed using a biocompatible coating.

\section{Polymyxin B-immobilised fibre column}

Polymyxin B (PMX)-immobilised fibre column haemoperfusion (Toraymyxin, Toray Industries, Tokyo, Japan) is the most commonly used approach, and has been used for the treatment of septic shock since 1994 in Japan and since 2002 in Europe. It has gained popularity worldwide in recent years, especially after the landmark EUPHAS (Early Use of Polymyxin B Hemoperfusion in Abdominal Sepsis) study. ${ }^{21}$ The PMX is a group of cyclic cationic polypeptide antibiotics derived from Bacillus polymyxa. Endotoxins are heat and $\mathrm{pH}$ stable, and thus can be difficult to remove from protein-rich solutions such as blood. The PMX is capable of binding and neutralising endotoxins. Nephrotoxicity and neurotoxicity, however, are very common and thus limit their clinical use. ${ }^{22}$ To overcome this problem, PMX is immobilised onto polystyrene fibres that effectively remove endotoxin without leaching. The blood is perfused at a rate of 80 to 100 $\mathrm{mL} / \mathrm{min}$ through a PMX-immobilised fibre column. Anticoagulation is achieved using unfractionated heparin, low-molecular-weight heparin, or the protease inhibitor nafamostat mesylate. Treatment usually lasts for 2 to 27 hours once or in some patients up to 4 times, depending on the clinical response. Three meta-analyses (approximately 1000 patients) were published before 2015: Studies by Mitaka and Tomita ${ }^{23}$ (17 studies, 975 patients) and Cruz et $\mathrm{al}^{24}$ (28 studies, 1425 patients) included both randomised controlled trials (RCTs) and observational studies. When reported, Gramnegative infections were identified in approximately $70 \%$ of patients (range, $37.9 \%-100 \%$ in individual studies). In general, PMX treatment led to significant haemodynamic improvement with a reduction in the use of inotropic agents/vasopressors in patients with sepsis. Moreover, it was associated with a decreased endotoxin level, modulation of inflammatory markers, and improvement of the $\mathrm{PaO}_{2} / \mathrm{FiO}_{2}$ ratio (ratio of the partial pressure of oxygen in arterial blood to the inspired oxygen fraction) in most included studies. ${ }^{23,24}$ Treatment by PMX significantly reduced 28-day mortality compared with conventional therapy. The metaanalysis by Zhou et $\mathrm{al}^{25}$ ( 8 studies, 370 patients) included RCTs only and focused on mortality, and showed significant survival benefit compared with conventional treatment. Only a few clinically important adverse effects were reported during PMX haemoperfusion, including cartridge clotting, hypotension, and hypersensitivity. Nonetheless, the largest multicentre RCT (232 patients) testing the performance of PMX haemoperfusion in peritonitis-induced septic shock was published in
April 2015, and reported contrasting findings. ${ }^{26}$ No significant differences in 28-day mortality $(27.7 \%$ in PMX-treated group vs $19.5 \%$ in controls; $\mathrm{P}=0.14$ ), haemodynamic patterns, or organ failure evolution were observed. This negative result was similar to a large retrospective study (642 patients) by Iwagami et $\mathrm{al}^{27}$ who examined the effect of postoperative PMX haemoperfusion on peritonitis-induced septic shock. Patients treated with one or two PMX haemoperfusion sessions showed similar mortality at day $28(17 \%)$ to propensity-matched patients without PMX treatment (16.3\%). EUPHRATES (safety and efficacy of PMX haemoperfusion for septic shock study), a very large multicentre US-based phase III trial in patients with confirmed endotoxaemia, is currently underway and results should be available after July 2017..$^{28}$ Based on current evidence, the clinical benefit of PMX haemoperfusion in Gramnegative sepsis is unclear. Moreover, the cost of individual haemoperfusion cartridges is very high (approximately HK\$40000 per cartridge) and limits its clinical use in local settings. Currently, PMXimmobilised fibre column haemoperfusion is not available in Hong Kong.

\section{MATISSE-Fresenius system}

The MATISSE-Fresenius system (Fresenius SE, Bad Homburg, Germany) binds endotoxins to human albumin. The extracorporeal circuit is maintained by the Fresenius haemoadsorption machine using the MATISSE haemoadsorber that contains human serum albumin immobilised on polymethacrylate beads. Trends in the improvement of morbidity and organ dysfunction were reported in initial non-randomised studies, ${ }^{29,30}$ although a subsequent multicentre RCT could not identify any significant clinical benefit, which then limited its clinical use. ${ }^{31}$ Currently, the MATISSE-Fresenius system is not available in Hong Kong.

\section{Alteco Lipopolysaccharide Adsorber}

The Alteco LPS Adsorber (Alteco Medical AB, Lund, Sweden) captures endotoxins using specially designed synthetic peptides. This device was launched in 2006. Tailor-made synthetic peptides with a high affinity for endotoxins are attached to the surface of the polyethylene plates using a covalent bonding technique. Clinical experience with this device is scarce, and is limited mainly to case reports and case series. ${ }^{32-34}$ In general, these case series report a shorter vasopressor infusion duration in adsorber-treated patients compared with controls. Only one underpowered RCT has been published by local investigators. ${ }^{35}$ The study was terminated early and showed no significant clinical benefit (disease severity score, vasopressor use, length of study, and 28-day mortality) following the addition of the Alteco LPS Adsorber to conventional therapy 
in patients who had intra-abdominal sepsis with shock. ${ }^{35}$ The side-effect profile of this novel device was acceptable but a recent ex-vivo experimental study showed that the Alteco LPS Adsorber could not achieve acceptable LPS clearance in serum, heparinised plasma, or whole blood. ${ }^{36}$ Therefore, the potential benefit of the Alteco LPS Adsorber in sepsis is not clear.

\section{Cytokines haemoadsorptive device}

Several cytokine-absorbing columns have been tested in animal studies, showing excellent adsorption rates for inflammatory cytokines such as TNF- $\alpha$, IL-1 $\beta$, IL-6, and IL-8. ${ }^{37}$ Human data are limited to case reports and case series. ${ }^{38-40}$ CytoSorb (CytoSorbents Corporation; Monmouth Junction [NJ], US) is a novel synthetic haemabsorption column that targets inflammatory mediators. ${ }^{41}$ It is currently the only European-approved extracorporeal device for cytokine haemoadsorption. Case reports show good cytokine clearance and haemodynamic improvement with this device. ${ }^{41-44}$ Further studies focused on clinically relevant endpoints are highly recommended. CytoSorb is not available in Hong Kong.

\section{High-adsorption haemofiltration}

The AN69 and polymethylmethacrylate (PMMA) membrane haemofilters are the currently available options for performing high-adsorption haemofiltration in septic patients. Both have a high cytokine adsorption capacity but surface treatment can further modify their haemoadsorptive properties. $^{45-47}$

\section{oXiris haemofilter}

oXiris (Gambro Hospal, Stockholm, Sweden) is an AN69-based membrane haemofilter that is surfacetreated with a polyethyleneimine and grafted with heparin (Table 2). The AN69 core membrane has superior cytokine-binding capacity compared with the traditional polysulphone membrane. Surface treatment with polyethyleneimine enhances endotoxin capture, ${ }^{48}$ while heparin coating reduces membrane thrombogenicity, and prolongs the filter life and improves efficiency. A case-control study by Shum et $\mathrm{al}^{49}$ involving Gram-negative septicaemic patients $(n=6)$ showed that oXiris continuous venovenous haemofiltration $(\mathrm{CVVH})$ was associated with a greater reduction in Sequential Organ Failure Assessment score compared with conventional polysulphone-based CVVH $(n=24)$. Subsequent large case series $(n=40)$ suggested that oXiris treatment had a positive effect on haemodynamics with a reduction in cytokine levels (IL-6). ${ }^{50}$ Treatment usually lasts for 72 hours (manufacturer's recommendation) and costs approximately HK\$8000 per haemofilter. As of mid 2015, at least five public hospitals in Hong Kong have clinical experience with oXiris haemofilters in the treatment of septic shock. A large-scale RCT will be necessary to determine the potential benefit of this device, however.

\section{Polymethylmethacrylate haemofilter}

The PMMA membrane has a higher cytokine adsorption capacity than the traditional polyacrylonitrile and polysulphone membrane. ${ }^{51}$ Membrane binding site saturation is one of the main concerns during treatment involving highly adsorptive haemofiltration. The PMMA haemofilter can maintain its cytokine adsorption capacity for at least 24 hours after being changed. ${ }^{52}$ The initial clinical experience of PMMA continuous haemodiafiltration in the treatment of sepsis is encouraging, with significant haemodynamic improvement and potential survival benefit. ${ }^{53,54} \mathrm{~A}$ local RCT (Australian New Zealand Clinical Trial Registry ACTRN12611000652976) that is aimed at investigating the clinical benefit of PMMA-based CVVH in patients with septic shock and AKI is currently underway. Treatment usually lasts for 24 to 48 hours and costs approximately HK\$300 per haemofilter.

TABLE 2. Characteristics of locally available filters used in high cut-off haemodialysis, highly adsorptive haemofiltration, and plasmapheresis

\begin{tabular}{|c|c|c|c|c|c|c|c|c|}
\hline Company & Filter name & Material & Therapy mode & $\begin{array}{c}\text { Effective surface } \\
\text { area }\left(m^{2}\right)\end{array}$ & $\begin{array}{c}\text { Cut-off } \\
\text { (kDa) }\end{array}$ & Machine & $\begin{array}{l}\text { Blood flow } \\
\text { (mL/min) }\end{array}$ & $\begin{array}{c}\text { Treatment } \\
\text { time (hours) }\end{array}$ \\
\hline FMC & EMiC 2 & Polysulphone & CVVHD & 1.8 & 40 & $\begin{array}{l}\text { Multifiltrate } \\
\text { AK200US }\end{array}$ & $100-350$ & 72 (maximum) \\
\hline Gambro/Baxter & septeX & PAES & CVVHD & 1.1 & 45 & Prismaflex & $80-400$ & 24 (maximum) \\
\hline Gambro/Baxter & oXiris & AN69 ST & CVVH/CVVHDF & 1.0 & $\sim 20$ & Prismaflex & $100-250$ & 72 (maximum) \\
\hline Toray & BG2.1U & PMMA & $\begin{array}{c}\text { CVVH/CVVHD/ } \\
\text { CVVHDF }\end{array}$ & 2.1 & $\sim 20$ & $\begin{array}{c}\text { Multifiltrate } \\
\text { AK200US } 5008\end{array}$ & $150-350$ & $24-48$ \\
\hline FMC & PlasmaFlux & Polysulphone & Plasmapheresis & 0.6 & $400-800$ & Multifiltrate & $80-250$ & $2-4$ \\
\hline
\end{tabular}

Abbreviations: $\mathrm{CVVH}=$ continuous venovenous haemofiltration; $\mathrm{CVVHD}=$ continuous venovenous haemodialysis; $\mathrm{CVVHDF}=$ continuous venovenous haemodiafiltration; FMC = Fresenius Medical Care; PAES = polyarylethersulphone; PMMA = polymethylmethacrylate 


\section{High-volume haemofiltration}

In 2002, HVHF was defined as $>35 \mathrm{~mL} / \mathrm{kg} / \mathrm{h}$, based on recommendations from the Acute Dialysis Quality Initiative Workgroup..$^{55}$ Nonetheless in clinical practice, $35 \mathrm{~mL} / \mathrm{kg} / \mathrm{h}$ is not that high and can be achieved with ease, especially in those with low body weight. To clarify this issue, Honore et al ${ }^{56}$ defined continuous HVHF as 50 to $70 \mathrm{~mL} / \mathrm{kg} / \mathrm{h}$, and 100 to $120 \mathrm{~mL} / \mathrm{kg} / \mathrm{h}$ for 4 to 8 hours followed by conventional CVVH as pulse HVHF. In addition, HVHF is regarded as effective blood purification therapy because circulating inflammatory mediators are mostly water-soluble and range between $5 \mathrm{kDa}$ and $60 \mathrm{kDa}$. They are more effectively removed by convective means than by diffusion techniques. Moreover, haemofilter membranes have some adsorptive properties that allow the removal of mediators with a molecular weight higher than the membrane cut-off point. It is clear that conventional haemofiltration with low ultrafiltration rates is ineffective for cytokine removal. ${ }^{2,3}$ Increasing the ultrafiltration flow rate can increase the adsorption capacity of the haemofilter because of its effect on transmembrane pressure (greater membrane site recruitment) and the exposure of more available adsorptive surface area. ${ }^{57}$ Only two RCTs that investigated the potential benefit of HVHF over conventional CVVH in septic patients were available before the publication of the landmark trial (highvolume versus standard-volume haemofiltration for septic shock patients with acute kidney injury study) in $2013 .{ }^{57,58}$ Cole et $\mathrm{al}^{57}$ performed the first randomised crossover clinical trial that involved 11 patients with septic shock and multi-organ failure. Patients were assigned to either 8 hours of HVHF $(6 \mathrm{~L} / \mathrm{h})$ or 8 hours of standard CVVH $(1 \mathrm{~L} / \mathrm{h})$ in a random order. The results showed that HVHF was associated with a greater reduction in vasopressor use. A study by Boussekey et al ${ }^{58}$ (HVHF $65 \mathrm{~mL} / \mathrm{kg} / \mathrm{h}$ vs control $35 \mathrm{~mL} / \mathrm{kg} / \mathrm{h} ; \mathrm{n}=20$ ) yielded similar findings and showed no survival benefit of HVHF over conventional CVVH. Multiple non-randomised studies showed decreased mortality with HVHF for septic shock patients but most of the studies were relatively small. ${ }^{59-61}$ Despite the initially encouraging results, HVHF has not gained in popularity because the use of a large volume of ultrapure replacement solution equates to significant increases in treatment cost, risk of severe electrolyte disturbance, and nursing workload. The landmark IVORIE study was published in 2013. ${ }^{62}$ This multicentre RCT involved 140 critically ill septic shock patients who were randomised to receive either HVHF at $70 \mathrm{~mL} / \mathrm{kg} / \mathrm{h}$ or standard CVVH treatment at $35 \mathrm{~mL} / \mathrm{kg} / \mathrm{h}$. It showed neither significant survival benefit nor haemodynamic improvement for HVHF compared with standard treatment. Subsequently two metaanalyses (4 studies with approximately 500 patients) published in 2014 concluded that neither HVHF nor pulse HVHF offered any added clinical benefit when compared with standard-volume haemofiltration. ${ }^{63,64}$ Therefore, the routine use of HVHF for treatment of sepsis is not recommended.

\section{High cut-off haemodialysis/ haemofiltration}

Inflammatory mediators are relatively large (TNF- $\alpha$ : $17 \mathrm{kDa}$, IL-6: $26 \mathrm{kDa}$, and IL-8: $8 \mathrm{kDa}$ ), and are classified as middle molecules. The conventional high-flux haemofilter has a cut-off point at approximately $20 \mathrm{kDa}$ and is unlikely to achieve good cytokine clearance., ${ }^{2,3}$ The nominal cut-off point for $\mathrm{HCO}$ membranes ranges from 60 to 150 $\mathrm{kDa}$ and the clinical cut-off point in blood ranges from 40 to $100 \mathrm{kDa}^{65}$ This can greatly increase the sieving coefficients of various inflammatory mediators at the expense of loss of albumin (66 $\mathrm{kDa})$, antithrombin-III $(60 \mathrm{kDa})$, protein $\mathrm{C}(62$ $\mathrm{kDa}$ ), and many other vital proteins. Reducing the pore size slightly can limit vital protein loss but also decrease cytokine removal. Ex-vivo studies showed that HCO haemofiltration displayed the greatest consistency in cytokine removal when compared with standard haemofiltration. ${ }^{66}$ The CPFA and haemoadsorption appeared to offer a similar level of cytokine clearance to the $\mathrm{HCO}$ technique. Albumin loss was comparable between $\mathrm{HCO}$ haemofiltration, HCO haemodialysis, and $\mathrm{HCO}$ haemodiafiltration. ${ }^{66}$ Morgera et a ${ }^{67}$ published the first study on the use of HCO haemofiltration among septic shock patients and showed good IL-6 (but not TNF- $\alpha$ ) clearance. Subsequently, Morgera et $\mathrm{al}^{68}$ conducted an RCT that involved 30 septic AKI patients who were randomised to $\mathrm{HCO}$ or conventional haemofiltration. The HCO group showed a significant decline in vasopressor use and cytokine level. ${ }^{68}$ The largest RCT was the High Cut-Off Continuous Venovenous Hemodialysis (CVVHD) in Patients Treated for Acute Renal Failure After Systemic Inflammatory Response Syndrome (SIRS)/Septic Shock (HICOSS) study. ${ }^{69}$ The estimated sample size was 120 patients but the study was terminated early because of a lack of difference between the groups after 81 patients had been recruited. There was no difference in 28-day mortality, vasopressor use, duration of mechanical ventilation, length of stay in intensive care unit, or albumin level between the groups. ${ }^{69}$ This underpowered RCT (due to premature termination) cannot provide a clear answer about the potential benefit of $\mathrm{HCO}$ haemofiltration/haemodialysis in septic patients and a further large-scale prospective RCT is recommended. Only the septeX (Gambro Hospal, Stockholm, Sweden) and EMiC 2 (Fresenius SE, Bad Homburg, Germany) HCO haemofilters are available in Hong Kong (Table 2). Treatment usually lasts for 24 to 72 hours and costs approximately 
HK\$8000 per HCO haemofilter.

\section{Plasmapheresis and coupled plasma filtration adsorption}

The nominal cut-off point for the plasma filter ranges from 400 to $800 \mathrm{kDa}$ and therefore can achieve good cytokine removal with significant albumin loss (Table 2). Only three RCTs have been published to date. Busund et $\mathrm{al}^{70}$ published the largest RCT involving 106 adult septic patients randomised to receive either two sessions of plasmapheresis or standard therapy. Plasmapheresis offered better 28-day survival compared with the control group (67\% vs $47 \%$ ). Studies by Reeves et $\mathrm{al}^{71}$ and Long et $\mathrm{al}^{72}$ showed no survival benefit, however. Therefore, the debate regarding the benefit of plasmapheresis in sepsis continues. One important drawback of plasmapheresis is the significant loss of albumin, fibrinogen, antithrombin, and immunoglobulin that takes a long time to regenerate in the absence of post-treatment replacement. ${ }^{73}$ This problem can be resolved with the use of CPFA (Lynda, Bellco, Mirandola, Italy). This CPFA therapy comprises a plasma filter, a non-selective hydrophobic resin cartridge with high affinity for inflammatory mediators, and a high-flux haemofilter for convective solute removal (Fig). ${ }^{74}$ Only filtrated plasma has direct contact with the sorbents that have no biocompatibility problems when compared with direct haemoperfusion. Treatment lasts for approximately 10 hours and requires cartridge changes due to saturation problems. Livigni et $\mathrm{al}^{75}$ published the only multicentre RCT focused on patients with septic shock. Patients were randomised to standard treatment with or without CPFA. The CPFA therapy was performed daily for 5 days and lasted at least 10 hours/day. The estimated sample size was 330 patients but the study was terminated early on the grounds of futility after 192 patients had been recruited. No significant benefits for mortality, organ dysfunction, or intensive care unit stay were observed. Therefore, based on the available evidence, the routine use of CPFA for treatment of septic shock is not recommended. The CPFA is currently not available in Hong Kong.

\section{Conclusion}

Building on the concept of excessive inflammatory mediator release, blood purification techniques have emerged as an adjunctive therapy for patients with severe sepsis and septic AKI. They are effective in clearing endotoxin or inflammatory mediators and are well tolerated. Despite initially promising results, most blood purification techniques have not provided any sustainable mortality benefits. In severe sepsis, source control, early appropriate antibiotics, and haemodynamic support are the three most

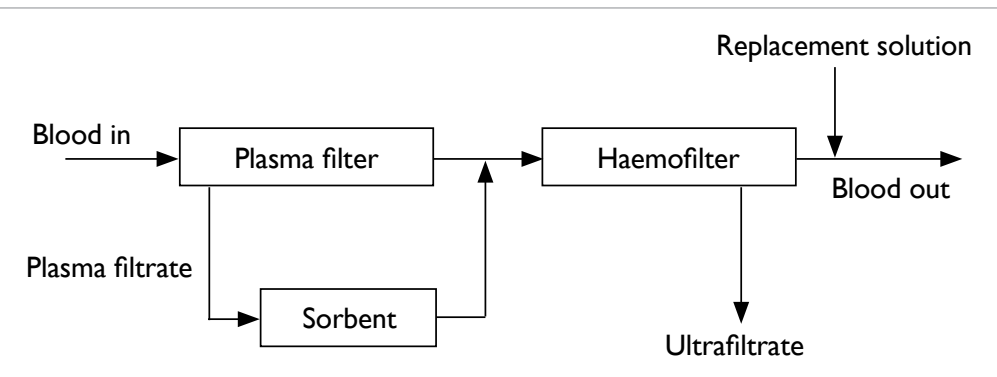

FIG. Schematic of coupled plasma filtration adsorption

important treatment components. ${ }^{76}$ As a supportive treatment, blood purification techniques may not significantly affect patient mortality. Since the outcome for septic patients has improved over time, much larger sample sizes will be needed to detect the relatively small effects of these new therapies on sepsis. ${ }^{77}$ Large-scale, well-designed, prospective RCTs are the way forward. The application of these novel techniques should be individualised but more specific recommendations must await further evidence.

\section{Declaration of interests}

All authors have disclosed no conflicts of interest.

\section{References}

1. Shum HP, Yan WW, Chan TM. Recent knowledge on the pathophysiology of septic acute kidney injury: A narrative review. J Crit Care 2016;31:82-9.

2. Cole L, Bellomo R, Hart G, et al. A phase II randomized, controlled trial of continuous hemofiltration in sepsis. Crit Care Med 2002;30:100-6.

3. Payen D, Mateo J, Cavaillon JM, et al. Impact of continuous venovenous hemofiltration on organ failure during the early phase of severe sepsis: a randomized controlled trial. Crit Care Med 2009;37:803-10.

4. Prince LR, Whyte MK, Sabroe I, Parker LC. The role of TLRs in neutrophil activation. Curr Opin Pharmacol 2011;11:397-403.

5. Nakayama H, Kurokawa K, Lee BL. Lipoproteins in bacteria: structures and biosynthetic pathways. FEBS J 2012;279:4247-68.

6. Zarbock A, Gomez H, Kellum JA. Sepsis-induced acute kidney injury revisited: pathophysiology, prevention and future therapies. Curr Opin Crit Care 2014;20:588-95.

7. Angus DC, van der Poll T. Severe sepsis and septic shock. N Engl J Med 2013;369:2063.

8. Gomez H, Ince C, De Backer D, et al. A unified theory of sepsis-induced acute kidney injury: inflammation, microcirculatory dysfunction, bioenergetics, and the tubular cell adaptation to injury. Shock 2014;41:3-11.

9. Suntharalingam G, Perry MR, Ward S, et al. Cytokine storm in a phase 1 trial of the anti-CD28 monoclonal antibody TGN1412. N Engl J Med 2006;355:1018-28.

10. Limaye AP, Kirby KA, Rubenfeld GD, et al. Cytomegalovirus 
reactivation in critically ill immunocompetent patients. JAMA 2008;300:413-22.

11. Boomer JS, To $\mathrm{K}$, Chang $\mathrm{KC}$, et al. Immunosuppression in patients who die of sepsis and multiple organ failure. JAMA 2011;306:2594-605.

12. Wang C, Sun J, Zheng J, et al. Low-dose hydrocortisone therapy attenuates septic shock in adult patients but does not reduce 28-day mortality: a meta-analysis of randomized controlled trials. Anesth Analg 2014;118:346-57.

13. Kalil AC, Sun J. Low-dose steroids for septic shock and severe sepsis: the use of Bayesian statistics to resolve clinical trial controversies. Intensive Care Med 2011;37:420-9.

14. Alejandria MM, Lansang MA, Dans LF, Mantaring JB 3rd. Intravenous immunoglobulin for treating sepsis, severe sepsis and septic shock. Cochrane Database Syst Rev 2013;(9):CD001090.

15. Bernard GR, Francois B, Mira JP, et al. Evaluating the efficacy and safety of two doses of the polyclonal antitumor necrosis factor-alpha fragment antibody AZD9773 in adult patients with severe sepsis and/or septic shock: randomized, double-blind, placebo-controlled phase IIb study. Crit Care Med 2014;42:504-11.

16. Ronco C, Tetta C, Mariano F, et al. Interpreting the mechanisms of continuous renal replacement therapy in sepsis: the peak concentration hypothesis. Artif Organs 2003;27:792-801.

17. Honoré PM, Matson JR. Extracorporeal removal for sepsis: Acting at the tissue level-the beginning of a new era for this treatment modality in septic shock. Crit Care Med 2004;32:896-7.

18. Di Carlo JV, Alexander SR. Hemofiltration for cytokinedriven illnesses: the mediator delivery hypothesis. Int J Artif Organs 2005;28:777-86.

19. Peng Z, Singbartl K, Simon P, et al. Blood purification in sepsis: a new paradigm. Contrib Nephrol 2010;165:322-8.

20. Rimmelé T, Kellum JA. Clinical review: blood purification for sepsis. Crit Care 2011;15:205.

21. Cruz DN, Antonelli M, Fumagalli R, et al. Early use of polymyxin $\mathrm{B}$ hemoperfusion in abdominal septic shock: the EUPHAS randomized controlled trial. JAMA 2009;301:2445-52.

22. Shoji H. Extracorporeal endotoxin removal for the treatment of sepsis: endotoxin adsorption cartridge (Toraymyxin). Ther Apher Dial 2003;7:108-14.

23. Mitaka C, Tomita M. Polymyxin B-immobilized fiber column hemoperfusion therapy for septic shock. Shock 2011;36:332-8.

24. Cruz DN, Perazella MA, Bellomo R, et al. Effectiveness of polymyxin B-immobilized fiber column in sepsis: a systematic review. Crit Care 2007;11:R47.

25. Zhou F, Peng Z, Murugan R, Kellum JA. Blood purification and mortality in sepsis: a meta-analysis of randomized trials. Crit Care Med 2013;41:2209-20.

26. Payen DM, Guilhot J, Launey Y, et al. Early use of polymyxin B hemoperfusion in patients with septic shock due to peritonitis: a multicenter randomized control trial. Intensive Care Med 2015;41:975-84.

27. Iwagami M, Yasunaga $H$, Doi K, et al. Postoperative polymyxin $\mathrm{B}$ hemoperfusion and mortality in patients with abdominal septic shock: a propensity-matched analysis. Crit Care Med 2014;42:1187-93.

28. Klein DJ, Foster D, Schorr CA, Kazempour K, Walker PM, Dellinger RP. The EUPHRATES trial (Evaluating the Use of
Polymyxin B Hemoperfusion in a Randomized controlled trial of Adults Treated for Endotoxemia and Septic shock): study protocol for a randomized controlled trial. Trials 2014;15:218.

29. Ullrich H, Jakob W, Frohlich D, et al. A new endotoxin adsorber: first clinical application. Ther Apher 2001;5:32634.

30. Staubach KH, Boehme M, Zimmermann M, Otto V. A new endotoxin adsorption device in Gram-negative sepsis: use of immobilized albumin with the MATISSE adsorber. Transfus Apher Sci 2003;29:93-8.

31. Reinhart K, Meier-Hellmann A, Beale R, et al. Open randomized phase II trial of an extracorporeal endotoxin adsorber in suspected Gram-negative sepsis. Crit Care Med 2004;32:1662-8.

32. Kulabukhov VV. Use of an endotoxin adsorber in the treatment of severe abdominal sepsis. Acta Anaesthesiol Scand 2008;52:1024-5.

33. Yaroustovsky M, Abramyan M, Popok Z, et al. Preliminary report regarding the use of selective sorbents in complex cardiac surgery patients with extensive sepsis and prolonged intensive care stay. Blood Purif 2009;28:227-33.

34. Ala-Kokko TI, Laurila J, Koskenkari J. A new endotoxin adsorber in septic shock: observational case series. Blood Purif 2011;32:303-9.

35. Shum HP, Leung YW, Lam SM, Chan KC, Yan WW. Alteco endotoxin hemoadsorption in Gram-negative septic shock patients. Indian J Crit Care Med 2014;18:783-8.

36. Harm S, Falkenhagen D, Hartmann J. Endotoxin adsorbents in extracorporeal blood purification: do they fulfill expectations? Int J Artif Organs 2014;37:222-32.

37. Taniguchi T. Cytokine adsorbing columns. Contrib Nephrol 2010;166:134-41.

38. Kellum JA, Venkataraman R, Powner D, Elder M, Hergenroeder G, Carter M. Feasibility study of cytokine removal by hemoadsorption in brain-dead humans. Crit Care Med 2008;36:268-72.

39. Kobe Y, Oda S, Matsuda K, Nakamura M, Hirasawa H. Direct hemoperfusion with a cytokine-adsorbing device for the treatment of persistent or severe hypercytokinemia: a pilot study. Blood Purif 2007;25:446-53.

40. Tsuchida K, Takemoto Y, Sugimura K, Yoshimura R, Nakatani T. Direct hemoperfusion by using Lixelle column for the treatment of systemic inflammatory response syndrome. Int J Mol Med 2002;10:485-8.

41. Morris C, Gray L, Giovannelli M. Early report: The use of CytoSorb haemabsorption column as an adjunct in managing severe sepsis: initial experiences, review and recommendations. J Intensive Care Soc 2015;16:257-64.

42. Hinz B, Jauch O, Noky T, Friesecke S, Abel P, Kaiser R. CytoSorb, a novel therapeutic approach for patients with septic shock: a case report. Int J Artif Organs 2015;38:4614.

43. Wiegele M, Krenn CG. CytoSorb in a patient with Legionella pneumonia-associated rhabdomyolysis: a case report. ASAIO J 2015;61:e14-6.

44. Hetz H, Berger R, Recknagel P, Steltzer H. Septic shock secondary to beta-hemolytic streptococcus-induced necrotizing fasciitis treated with a novel cytokine adsorption therapy. Int J Artif Organs 2014;37:422-6.

45. Bouman CS, van Olden RW, Stoutenbeek CP. Cytokine filtration and adsorption during pre- and postdilution hemofiltration in four different membranes. Blood Purif 
$1998 ; 16: 261-8$

46. De Vriese AS, Colardyn FA, Philippé JJ, Vanholder RC, De Sutter JH, Lameire NH. Cytokine removal during continuous hemofiltration in septic patients. J Am Soc Nephrol 1999;10:846-53.

47. Hirasawa H, Oda S, Matsuda K. Continuous hemodiafiltration with cytokine-adsorbing hemofilter in the treatment of severe sepsis and septic shock. Contrib Nephrol 2007;156:365-70.

48. Mitzner S, Schneidewind J, Falkenhagen D, Loth F, Klinkmann H. Extracorporeal endotoxin removal by immobilized polyethylenimine. Artif Organs 1993;17:77581.

49. Shum HP, Chan KC, Kwan MC, Yan WW. Application of endotoxin and cytokine adsorption haemofilter in septic acute kidney injury due to Gram-negative bacterial infection. Hong Kong Med J 2013;19:491-7.

50. Turani F, Candidi F, Barchetta R, et al. Continuous renal replacement therapy with the adsorbent membrane oXiris in septic patients: a clinical experience. Crit Care 2013;17 Suppl 2:63.

51. Matsuda K, Hirasawa H, Oda S, Shiga H, Nakanishi K. Current topics on cytokine removal technologies. Ther Apher 2001;5:306-14.

52. Nakada TA, Hirasawa H, Oda S, Shiga H, Matsuda K. Blood purification for hypercytokinemia. Transfus Apher Sci 2006;35:253-64.

53. Nakada TA, Oda S, Matsuda K, et al. Continuous hemodiafiltration with PMMA hemofilter in the treatment of patients with septic shock. Mol Med 2008;14:257-63.

54. Matsuda K, Moriguchi T, Harii N, Yanagisawa M, Harada D, Sugawara H. Comparison of efficacy between continuous hemodiafiltration with a PMMA high-performance membrane dialyzer and a PAN membrane hemofilter in the treatment of septic shock patients with acute renal failure. Contrib Nephrol 2011;173:182-90.

55. Kellum JA, Mehta RL, Angus DC, Palevsky P, Ronco C, ADQI Workgroup. The first international consensus conference on continuous renal replacement therapy. Kidney Int 2002;62:1855-63.

56. Honore PM, Joannes-Boyau O, Boer W, Collin V. Highvolume hemofiltration in sepsis and SIRS: current concepts and future prospects. Blood Purif 2009;28:1-11.

57. Cole L, Bellomo R, Journois D, Davenport P, Baldwin I, Tipping P. High-volume haemofiltration in human septic shock. Intensive Care Med 2001;27:978-86.

58. Boussekey N, Chiche A, Faure K, et al. A pilot randomized study comparing high and low volume hemofiltration on vasopressor use in septic shock. Intensive Care Med 2008;34:1646-53.

59. Cornejo R, Downey P, Castro R, et al. High-volume hemofiltration as salvage therapy in severe hyperdynamic septic shock. Intensive Care Med 2006;32:713-22.

60. Joannes-Boyau O, Rapaport S, Bazin R, Fleureau C, Janvier G. Impact of high volume hemofiltration on hemodynamic disturbance and outcome during septic shock. ASAIO J 2004;50:102-9.

61. Piccinni P, Dan M, Barbacini S, et al. Early isovolaemic haemofiltration in oliguric patients with septic shock. Intensive Care Med 2006;32:80-6.
62. Joannes-Boyau O, Honoré PM, Perez P, et al. High-volume versus standard-volume haemofiltration for septic shock patients with acute kidney injury (IVOIRE study): a multicentre randomized controlled trial. Intensive Care Med 2013;39:1535-46.

63. Lehner GF, Wiedermann CJ, Joannidis M. High-volume hemofiltration in critically ill patients: a systematic review and meta-analysis. Minerva Anestesiol 2014;80:595-609.

64. Clark E, Molnar AO, Joannes-Boyau O, Honoré PM, Sikora L, Bagshaw SM. High-volume hemofiltration for septic acute kidney injury: a systematic review and meta-analysis. Crit Care 2014;18:R7.

65. Haase M, Bellomo R, Morgera S, Baldwin I, Boyce N. High cut-off point membranes in septic acute renal failure: a systematic review. Int J Artif Organs 2007;30:1031-41.

66. Atan R, Crosbie D, Bellomo R. Techniques of extracorporeal cytokine removal: a systematic review of the literature. Blood Purif 2012;33:88-100.

67. Morgera S, Rocktäschel J, Haase M, et al. Intermittent high permeability hemofiltration in septic patients with acute renal failure. Intensive Care Med 2003;29:1989-95.

68. Morgera S, Haase M, Kuss T, et al. Pilot study on the effects of high cutoff hemofiltration on the need for norepinephrine in septic patients with acute renal failure. Crit Care Med 2006;34:2099-104.

69. Honore P, Beck W, editors. High cut-off continuous venovenous hemodialysis (CVVHD) in patients treated for acute renal failure after systemic inflammatory response syndrome (SIRS)/septic shock (HICOSS). Proceedings of the 10th Congress of the World Federation of Societies of Intensive and Critical Care Medicine (WFSICCM); 2009 Aug 28-Sep 1; Florence, Italy.

70. Busund R, Koukline V, Utrobin U, Nedashkovsky E. Plasmapheresis in severe sepsis and septic shock: a prospective, randomised, controlled trial. Intensive Care Med 2002;28:1434-9.

71. Reeves JH, Butt WW, Shann F, et al. Continuous plasmafiltration in sepsis syndrome. Plasmafiltration in Sepsis Study Group. Crit Care Med 1999;27:2096-104.

72. Long EJ, Shann F, Pearson G, Buckley D, Butt W. A randomised controlled trial of plasma filtration in severe paediatric sepsis. Crit Care Resusc 2013;15:198-204.

73. Stegmayr B, Abdel-Rahman EM, Balogun RA. Septic shock with multiorgan failure: from conventional apheresis to adsorption therapies. Semin Dial 2012;25:171-5.

74. Formica $M$, Inguaggiato $\mathrm{P}$, Bainotti $\mathrm{S}$, Wratten ML. Coupled plasma filtration adsorption. Contrib Nephrol 2007;156:405-10.

75. Livigni S, Bertolini G, Rossi C, et al. Efficacy of coupled plasma filtration adsorption (CPFA) in patients with septic shock: a multicenter randomised controlled clinical trial. BMJ Open 2014;4:e003536.

76. Dellinger RP, Levy MM, Rhodes A, et al. Surviving sepsis campaign: international guidelines for management of severe sepsis and septic shock: 2012. Crit Care Med 2013;41:580-637.

77. Kaukonen KM, Bailey M, Suzuki S, Pilcher D, Bellomo R. Mortality related to severe sepsis and septic shock among critically ill patients in Australia and New Zealand, 20002012. JAMA 2014;311:1308-16 